Supplement of Hydrol. Earth Syst. Sci., 21, 5243-5261, 2017

https://doi.org/10.5194/hess-21-5243-2017-supplement

(C) Author(s) 2017. This work is distributed under

the Creative Commons Attribution 3.0 License.

(c) (1)

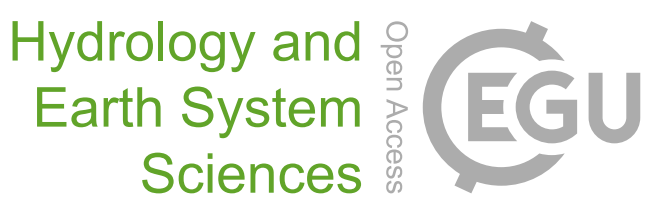

Supplement of

\title{
Pesticide fate on catchment scale: conceptual modelling of stream CSIA data
}

Stefanie R. Lutz et al.

Correspondence to: Stefanie R. Lutz (stefanie.lutz@ufz.de)

The copyright of individual parts of the supplement might differ from the CC BY 3.0 License. 


\section{Contents}

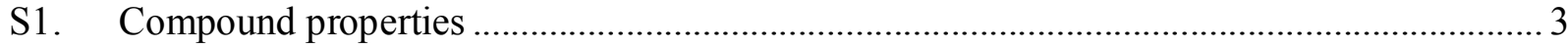

S2. Formulation of the storage selection (SAS) function ....................................................... 4

S3. Measured concentrations and $\delta^{13} \mathrm{C}$-values at the plot, drain, and catchment outlet for S-

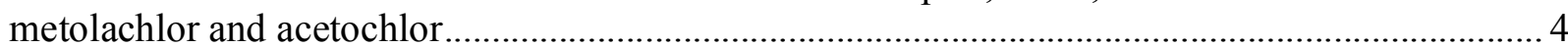

S4. Calculation of the extent of degradation for a sample at the catchment outlet.................... 6

S5. Objective functions for optimization and parameter identifiability via optimization ........... 8

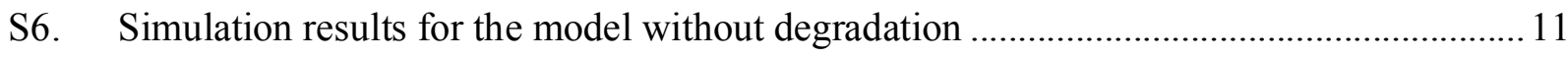

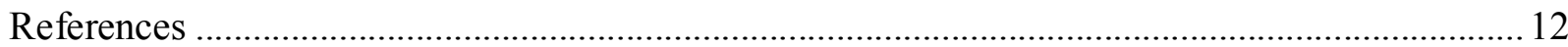




\section{S1. Compound properties}

2 Metolachlor consists of four stable stereoisomers; S-metolachlor (Table S1) denotes the two

3 herbicidally active stereoisomers of metolachlor. S-metolachlor is classified as moderately

4 water-soluble $\left(480 \mathrm{mg} \mathrm{L}^{-1}\right)$ and moderately mobile in soil ( $\log K_{\mathrm{oc}}$ between 1.79 and 2.57).

5 Acetochlor has a moderate solubility $\left(282 \mathrm{mg} \mathrm{L}^{-1}\right)$ and mobility in soil (Log $K_{\mathrm{oc}}$ of 2.19).

6 The current commercial formulations of metolachlor have been enriched to contain more than

$780 \%$ of the herbicidally active S-enantiomer (S-metolachlor), and progressively replaced racemic

8 metolachlor in the 2000s (Buser et al., 2000).

9 Table S1. Compound properties of the two study compounds. ${ }^{\text {a }}$

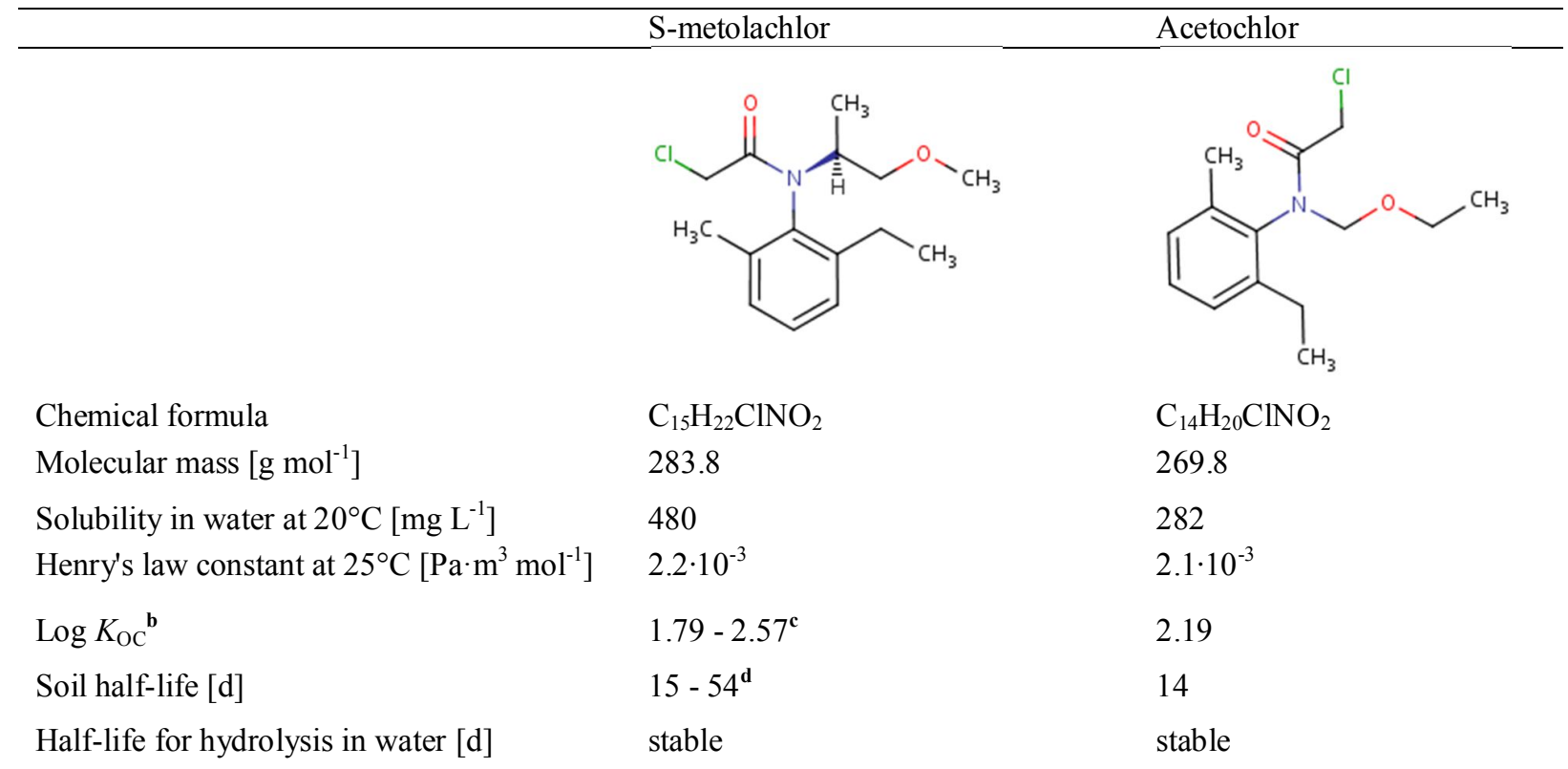

a Source: University of Hertfordshire (2013); TOXNET database (U.S. National Library of Medicine; http://toxnet.nlm.nih.gov).

b Soil organic carbon-water partition coefficient

c Alletto et al., 2013

d Lefrancq, 2014 
14 The SAS function was approximated by a beta distribution defined by the mixing parameter $m_{\mathrm{Q}}(\mathrm{t})$ (cf. van der Velde et al., 2015). The latter depends on the model parameters $\alpha_{\mathrm{Q}}$ and $\beta_{\mathrm{Q}}$ :

$m_{Q}(t)=\alpha_{Q}\left(1-\beta_{Q} \frac{S(t)-S_{\min }}{S_{\max }-S_{\min }}\right)$

\section{S2. Formulation of the storage selection (SAS) function}

where $S_{\min }$ and $S_{\max }$ are the minimum and maximum transport zone storage, respectively. The parameter $\alpha_{\mathrm{Q}}$ ranges between 0.2 and 1.9, and $\beta_{\mathrm{Q}}$ ranges between 0 and 0.95 (see Table 3). Under dry conditions, $m_{\mathrm{Q}}(\mathrm{t})$ approaches $\alpha_{\mathrm{Q}}$ and will primarily lead to old water discharge, whereas, under wet conditions, $m_{\mathrm{Q}}(\mathrm{t})$ approaches $\alpha_{\mathrm{Q}}\left(1-\beta_{\mathrm{Q}}\right)$ and will primarily lead to young water discharge. Hence, the SAS function results in preference for young water if $m_{\mathrm{Q}}(\mathrm{t})<1$, preference for old water if $m_{\mathrm{Q}}(\mathrm{t})>1$, and a uniform distribution if $m_{\mathrm{Q}}(\mathrm{t})=1$ (i.e., "random sampling" of outflow from storage; see Fig. 1 in van der Velde et al., 2015).

\section{S3. Measured concentrations and $\delta^{13} \mathrm{C}$-values at the plot, drain, and catchment outlet for S-metolachlor and acetochlor}

Table S2. Concentrations and $\delta^{13} \mathrm{C}$-values at the plot ( \pm standard deviation)

\begin{tabular}{llllll} 
Sample name & Date & \multicolumn{2}{c}{ S-metolachlor } & \multicolumn{2}{c}{ Acetochlor } \\
& & $\begin{array}{c}\text { Concentration } \\
{\left[\boldsymbol{\mu} \mathbf{~ L}^{-1}\right]}\end{array}$ & $\boldsymbol{\delta}^{\mathbf{1 3}} \mathbf{C}[\% \mathbf{~}]$ & $\begin{array}{l}\text { Concentration } \\
{\left[\boldsymbol{\mu g} \mathbf{~ L}^{-1}\right]}\end{array}$ & $\boldsymbol{\delta}^{\mathbf{1 3}} \mathbf{C}[\% \mathbf{~}]$ \\
\hline Application tank & & & $-31.9 \pm 0.31$ & & \\
PW4 & 10.04 .12 & $0.36 \pm 0.01$ & n.d. & 0.00 & 0.00 \\
PW5 & 17.04 .12 & $64.10 \pm 8.59$ & n.d. & $1.75 \pm 0.15$ & \\
PW7 & 02.05 .12 & $36.16 \pm 2.39$ & $-31.60 \pm 0.28$ & 0.00 & 0.00 \\
PW9 & 15.05 .12 & $48.73 \pm 1.50$ & n.d. & 0.00 & 0.00 \\
PW10 & 22.05 .12 & $40.85 \pm 1.37$ & $-32.20 \pm 0.14$ & $0.48 \pm 0.08$ & $-33.20 \pm 0.19$ \\
PW11 & 29.05 .12 & $27.12 \pm 0.75$ & $-32.10 \pm 0.29$ & $0.30 \pm 0.11$ & $-34.20 \pm 0.07$ \\
PW13 & 12.06 .12 & $19.08 \pm 0.75$ & n.d. & 0.00 & n.d. \\
PW14 & 19.06 .12 & $7.80 \pm 0.55$ & $-30.70 \pm 0.29$ & $0.23 \pm 0.00$ & $-29.90 \pm 0.32$ \\
PW17 & 10.07 .12 & $10.75 \pm 0.17$ & $-29.60 \pm 0.12$ & 0.00 & n.d. \\
PW18 & 16.07 .12 & $14.90 \pm 0.04$ & n.d. & 0.00 & n.d. \\
\hline
\end{tabular}


a not determined

28 Table S3. Concentrations at the drain outlet ( \pm standard deviation)

\begin{tabular}{llll} 
Sample name & Date & S-metolachlor $\left[\boldsymbol{\mu g} \mathbf{L}^{-1}\right]$ & Acetochlor $\left[\boldsymbol{\mu g} \mathbf{L}^{-1}\right]$ \\
\hline DW1 & 20.03 .12 & 0.000 & 0.000 \\
DW3 & 03.04 .12 & 0.000 & $0.226 \pm 0.009$ \\
DW4 & 10.04 .12 & 0.000 & 0.000 \\
DW5 & 17.04 .12 & $0.097 \pm 0.003$ & 0.000 \\
DW6 & 24.04 .12 & 0.000 & $0.501 \pm 0.007$ \\
DW7 & 02.05 .12 & $0.314 \pm 0.092$ & $0.226 \pm 0.005$ \\
DW8 & 09.05 .12 & 0.000 & $0.234 \pm 0.002$ \\
DW9 & 15.05 .12 & 0.000 & 0.000 \\
DW10 & 22.05 .12 & $2.208 \pm 1.319$ & $0.853 \pm 0.054$ \\
DW11 & 29.05 .12 & $0.284 \pm 0.161$ & 0.000 \\
DW12 & 05.06 .12 & $0.207 \pm 0.007$ & 0.000 \\
DW13 & 12.06 .12 & $0.363 \pm 0.027$ & 0.000 \\
DW14 & 19.06 .12 & $0.187 \pm 0.007$ & $0.330 \pm 0.002$ \\
DW15 & 26.06 .12 & $0.341 \pm 0.354$ & 0.000 \\
DW16 & 03.07 .12 & $0.338 \pm 0.049$ & 0.000 \\
DW17 & 10.07 .12 & $0.161 \pm 0.052$ & 0.000
\end{tabular}

30 Table S4. Concentrations and $\delta^{13} \mathrm{C}$-values at the catchment outlet ( \pm standard deviation)

\begin{tabular}{|c|c|c|c|c|c|}
\hline \multirow[t]{2}{*}{ Sample name } & \multirow[t]{2}{*}{ Date } & \multicolumn{2}{|c|}{ S-metolachlor } & \multicolumn{2}{|c|}{ Acetochlor } \\
\hline & & $\begin{array}{l}\text { Concentration } \\
{\left[\mu \mathrm{g} \mathrm{L}^{-1}\right]}\end{array}$ & $\delta^{13} \mathrm{C}[\% 0]$ & $\begin{array}{l}\text { Concentration } \\
{\left[\mu \mathrm{g} \mathrm{L}^{-1}\right]}\end{array}$ & $\delta^{13} \mathrm{C}[\%$ \\
\hline CW1 & 20.03 .12 & $0.07 \pm 0.01$ & n.d. ${ }^{\mathbf{a}}$ & 0.00 & n.d. \\
\hline CW2 & 27.03 .12 & 0.00 & n.d. & $0.20 \pm 0.01$ & n.d. \\
\hline CW3 & 03.04 .12 & 0.00 & n.d. & $0.21 \pm 0.00$ & n.d. \\
\hline CW4 & 10.04 .12 & 0.00 & n.d. & 0.00 & n.d. \\
\hline CW5 & 17.04 .12 & 0.00 & n.d. & 0.00 & n.d. \\
\hline CW6 & 24.04 .12 & 0.00 & n.d. & 0.00 & n.d. \\
\hline CW7- $\alpha$ & 02.05 .12 & 0.00 & n.d. & 0.00 & n.d. \\
\hline CW7- $\beta$ & 02.05 .12 & $1.06 \pm 0.00$ & n.d. & 0.00 & n.d. \\
\hline CW8 & 09.05 .12 & 0.00 & n.d. & $0.24 \pm 0.01$ & n.d. \\
\hline CW9 & 15.05 .12 & 0.00 & n.d. & 0.00 & n.d. \\
\hline CW10- $\alpha$ & 21.05 .12 & $62.09 \pm 1.63$ & $-32.20 \pm 0.18$ & $59.33 \pm 0.84$ & $-28.99 \pm 0.24$ \\
\hline CW10- $\beta$ & 21.05 .12 & $40.23 \pm 2.70$ & $-32.39 \pm 0.18$ & $29.18 \pm 0.28$ & $-29.65 \pm 0.15$ \\
\hline
\end{tabular}




\begin{tabular}{|c|c|c|c|c|c|}
\hline CW10- $\gamma$ & 21.05 .12 & $16.38 \pm 0.53$ & $-31.59 \pm 0.70$ & $31.09 \pm 0.54$ & $-29.68 \pm 0.16$ \\
\hline CW11 & 29.05 .12 & $6.46 \pm 0.54$ & $-31.81 \pm 0.31$ & $1.08 \pm 0.16$ & $-29.76 \pm 0.29$ \\
\hline CW12 & 05.06 .12 & $1.21 \pm 0.27$ & n.d. & $0.31 \pm 0.00$ & n.d. \\
\hline CW13- $\alpha$ & 07.06 .12 & $0.45 \pm 0.03$ & n.d. & $0.49 \pm 0.06$ & n.d. \\
\hline CW13- $\beta$ & 07.06 .12 & $2.79 \pm 0.32$ & n.d. & $1.07 \pm 0.02$ & n.d. \\
\hline CW13- $\gamma$ & 09.06 .12 & $1.67 \pm 0.05$ & n.d. & $0.54 \pm 0.02$ & n.d. \\
\hline CW14 & 19.06 .12 & $1.69 \pm 0.20$ & $-30.59 \pm 0.12$ & $0.40 \pm 0.05$ & $-25.61 \pm 0.87$ \\
\hline CW15 & 26.06 .12 & $0.04 \pm 0.00$ & n.d. & 0.00 & n.d. \\
\hline CW16- $\alpha$ & 28.06 .12 & $0.28 \pm 0.03$ & n.d. & 0.00 & n.d. \\
\hline CW16- $\beta$ & 28.06 .12 & $0.19 \pm 0.01$ & n.d. & 0.00 & n.d. \\
\hline CW16- $\gamma$ & 03.07 .12 & $0.17 \pm 0.01$ & n.d. & 0.00 & n.d. \\
\hline CW17- $\alpha$ & 06.07 .12 & $0.58 \pm 0.01$ & n.d. & 0.00 & n.d. \\
\hline CW17- $\beta$ & 07.07 .12 & $0.24 \pm 0.01$ & n.d. & $0.22 \pm 0.00$ & n.d. \\
\hline CW17- $\gamma$ & 07.07 .12 & $0.68 \pm 0.02$ & n.d. & 0.00 & n.d. \\
\hline CW17- $\chi$ & 07.07 .12 & $0.33 \pm 0.00$ & n.d. & 0.00 & n.d. \\
\hline CW18 & 17.07 .12 & $0.28 \pm 0.01$ & $-29.74 \pm 0.79$ & 0.00 & n.d. \\
\hline CW19 & 24.07 .12 & $0.17 \pm 0.07$ & n.d. & 0.00 & n.d. \\
\hline CW20 & 31.07 .12 & $0.14 \pm 0.00$ & n.d. & $1.89 \pm 0.00$ & n.d. \\
\hline CW21 & 08.08 .12 & $0.14 \pm 0.00$ & n.d. & 0.00 & n.d. \\
\hline CW22 & 14.08 .12 & $0.11 \pm 0.00$ & n.d. & $1.19 \pm 0.00$ & n.d. \\
\hline CW23 & 21.08 .12 & 0.00 & n.d. & 0.00 & n.d. \\
\hline CW24 & 20.11 .12 & $0.10 \pm 0.00$ & n.d. & 0.00 & n.d. \\
\hline
\end{tabular}

a not determined

\section{S4. Calculation of the extent of degradation for a sample at the catchment outlet}

34 A conservative estimate of the extent of degradation for some environmental sample can be 35 obtained from the Rayleigh equation approach (Elsner and Imfeld, 2016; Mariotti et al., 1981;

36 Rayleigh, 1896):

$$
f_{\text {deg }}=\left(\frac{R_{S}}{R_{0}}\right)^{\frac{1}{(\alpha-1)}}
$$

37 where $R_{0}$ is the isotope ratio (e.g., ${ }^{13} \mathrm{C} /{ }^{12} \mathrm{C}$ ) of the contaminant at the contamination source, $R_{\mathrm{S}}$ is 38 the isotope ratio of the contaminant in an environmental sample at some distance from the 39 source, $f_{\text {deg }}$ represents the remaining fraction of the contaminant in the sample relative to the 
40 source, and $\alpha$ is the kinetic isotope fractionation factor (commonly reported in per mil (\%) as the

41 kinetic isotopic enrichment factor; $\varepsilon=(\alpha-1)$, where $\alpha<1)$. In this study, we applied Eq. (S2) to 42 the simulated CSIA data at the catchment outlet, and calculated the extent of degradation based 43 on the Rayleigh equation approach as:

$$
D_{\text {Rayleigh }}[\%]=\left(1-f_{\text {deg }}\right) \cdot 100
$$

44 In order to evaluate the potential use of the Rayleigh equation approach for catchment-scale 45 applications, we compared $D_{\text {Rayleigh }}$ to the "true" extent of degradation at the catchment outlet 46 ( $\left.D_{\text {Sample }}\right)$, which is given by the ratio between the simulated outlet concentrations of Smetolachlor ( $C_{\text {met }}$; the sum of its light and heavy carbon isotopes) and a conservative tracer 48 $\left(C_{\text {trac }}\right)$ :

$$
D_{\text {Sample }}[\%]=\left(1-\frac{C_{m e t}}{C_{\text {trac }}}\right) \cdot 100
$$


51 Parameters were optimized against the $N_{\mathrm{C}}, N_{\mathrm{Q}}$ and $N_{\delta 13 \mathrm{C}}$ coefficients simultaneously by using the combined objective function $N_{\text {comb }}=\left(N_{\mathrm{Q}} / 6+N_{\mathrm{C}}+N_{\delta 13 \mathrm{C}}\right) /(13 / 6)$. The factor $1 / 6$ for $N_{\mathrm{Q}}$, which was determined via prior test calibration runs, ensures that all three terms contribute approximately evenly during the optimization process.

$N_{\mathrm{Q}}$ compares measured to modelled discharge at the catchment outlet, considering the best fit in a window of plus or minus one day to account for potential time lags of measured discharge in response to rainfall events:

$N_{Q}=1-\left(\frac{\min \left(\sum_{t=1}^{n}\left(Q_{t, \text { mod }}-Q_{t, \text { meas }}\right)^{2}, \sum_{t=1}^{n}\left(Q_{t-1, \text { mod }}-Q_{t, \text { meas }}\right)^{2}, \sum_{t=1}^{n}\left(Q_{t+1, \text { mod }}-Q_{t, \text { meas }}\right)^{2}\right)}{\sum_{t=1}^{n}\left(Q_{t, \text { meas }}-\overline{Q_{\text {meas }}}\right)^{2}}+0.03 \cdot f\right)$

$N_{C}=1-0.5 \cdot\left(\frac{\sum_{i=1}^{n} t w_{i} \cdot\left(C_{i, \text { mod }}-C_{i, \text { meas }}\right)^{2}}{\sum_{i=1}^{n} t w_{i} \cdot\left(C_{i, \text { meas }}-\overline{C_{\text {meas }}}\right)^{2}}+\frac{\sum_{i=1}^{n} t w_{i} \cdot\left(\ln \left(C_{i, \text { mod }}\right)-\ln \left(C_{i, \text { meas }}\right)\right)^{2}}{\sum_{i=1}^{n} t w_{i} \cdot\left(\ln \left(C_{i, \text { meas }}\right)-\overline{\left.\ln \left(C_{\text {meas }}\right)\right)^{2}}\right.}\right)$ 


$$
N_{\delta 13 C}=1-\frac{\sum_{i=1}^{n} t w_{i} \cdot\left(\delta^{13} C_{i, \text { mod }}-\delta^{13} C_{i, \text { meas }}\right)^{2}}{\sum_{i=1}^{n} t w_{i} \cdot\left(\delta^{13} C_{i, \text { meas }}-\overline{\delta^{13} C_{\text {meas }}}\right)^{2}}
$$

73 where $n$ is the total number of $\delta^{13} \mathrm{C}$-samples, and $\overline{\delta^{13} C_{m e a s}}$ is the mean of the measured $\delta^{13} \mathrm{C}$ 74 values.

respectively, and $t w_{\mathrm{i}}$ is the time-proportional weight of sample $i$ (with flow-proportional samples spanning more than a day considered as a daily sample). Note that the grab sample in November was considered as a daily value. The same $t w_{\mathrm{i}}$ is also used in the calculation of $N_{\delta 13 \mathrm{C}}$, which gives the deviations of the flow-proportionally weighted modelled $\left(\delta^{13} C_{\mathrm{i}, \mathrm{mod}}\right)$ from the measured carbon isotope ratios $\left(\delta^{13} C_{\mathrm{i}, \text { meas }}\right)$ :

Figure S1 shows the histograms of the 18 calibrated parameters from all 10,000 behavioural simulations. Most histograms have one clear maximum and thus indicate identifiability of the respective parameter. However, a few parameters exhibit flat histograms; these are $\beta_{\mathrm{Q}}$ and $\alpha_{\mathrm{ET}}$ for the flow-related parameters, and $f_{\mathrm{ex}}$ and $m_{\mathrm{IN}}$ for the parameters of the pesticide model. As $\beta_{\mathrm{Q}}$ determines the preference of old water in discharge from the transport zone and $\alpha_{\mathrm{ET}}$ defines the preference for young water in evapotranspiration, it was not possible to distinguish between the effects of evapotranspiration (ET) and old water discharge on pesticide concentrations in the study catchment. Accordingly, the amount of pesticide transfer in plant exudation following transport via ET, defined by $f_{\text {ex }}$, shows little parameter identifiability. Finally, the flat frequency distribution of $m_{\mathrm{IN}}$ indicates no clear tendency towards more or less pesticide input than assessed by the survey of pesticide applications. 

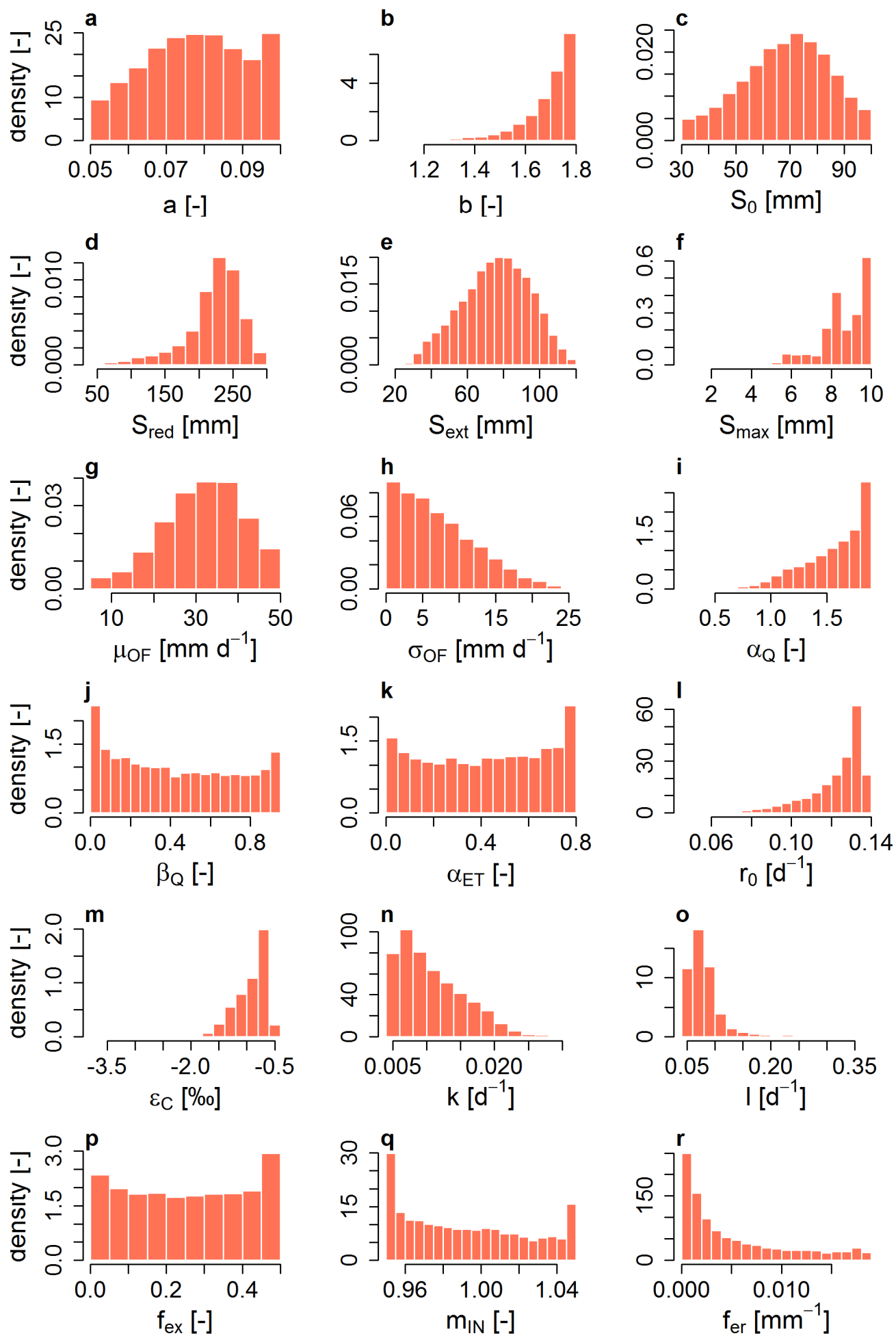

Figure S 1: Histograms (frequency distributions) of the 18 calibrated model parameters from the 


\section{S6. Simulation results for the model without degradation}

90 The model was run without pesticide degradation and calibrated against measured discharge and

91 concentrations in 1000 simulations. Figure S2 shows that this model setup fails to reproduce the

92 measured concentrations (Fig. S2c), even though erosion increased relative to the original model.

(a)

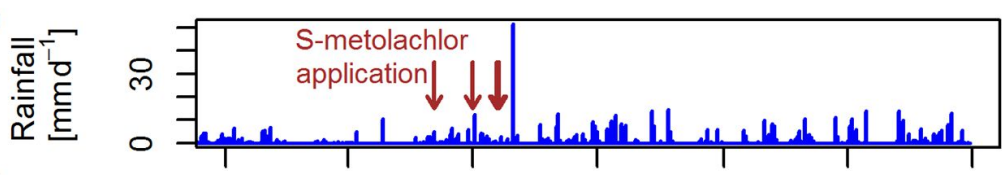

(b)

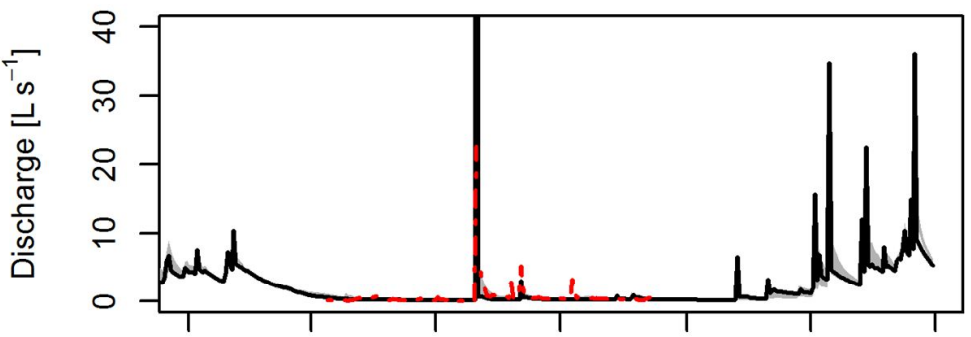

(c)

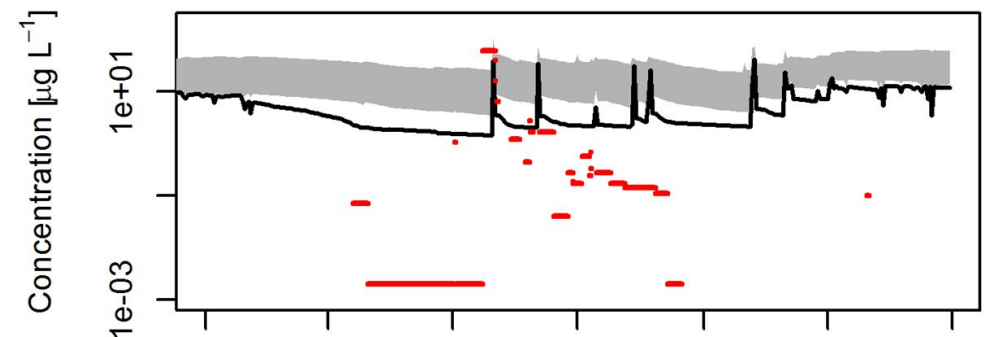

(d)

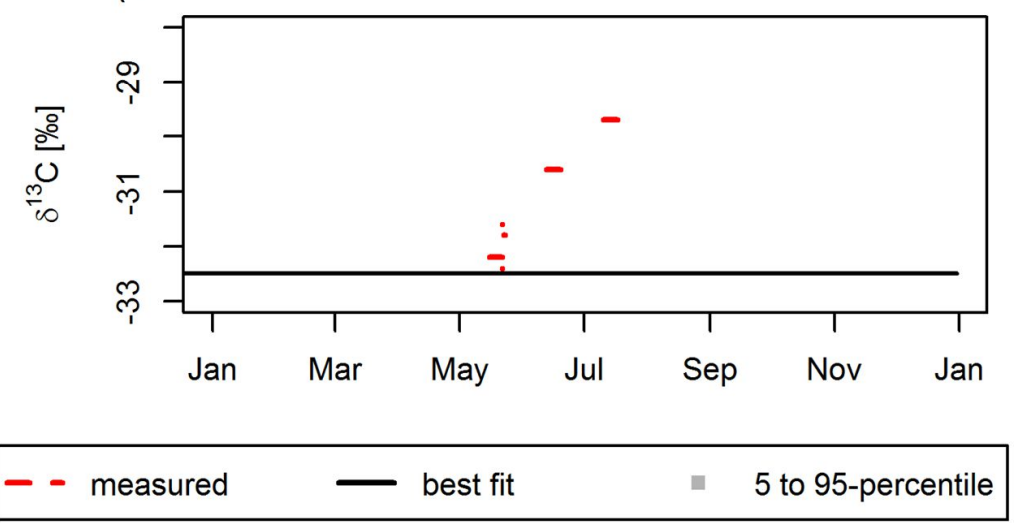

Figure S 2: Measured (red lines) and modelled time series for discharge (b), S-metolachlor concentrations (c; note the log-scaling) and $\delta^{13} \mathrm{C}$-values (d) at the catchment outlet in 2012 for the model without degradation (1000 calibration runs). The black line indicates the results of the calibration run with the best fit in terms of the mean of $N_{\mathrm{Q}} / 6, N_{\mathrm{C}}$, and $N_{\delta 13 \mathrm{C}}$. Shaded areas show the range between the 5- and 95-percentiles of all simulation results. Blue bars in (a) indicate daily precipitation and brown arrows indicate the dates of pesticide application. 
102 1. Alletto, L.; Benoit, P.; Bolognési, B.; Couffignal, M.; Bergheaud, V.; Dumény, V.;

103 Longueval, C.; Barriuso, E., Sorption and mineralisation of S-metolachlor in soils from fields

104 cultivated with different conservation tillage systems. Soil and Tillage Research 2013, 128, (0), 105 97-103, doi: 10.1016/j.still.2012.11.005.

106 2. Buser, H.-R.; Poiger, T.; Müller, M. D., Changed Enantiomer Composition of 107 Metolachlor in Surface Water Following the Introduction of the Enantiomerically Enriched 108 Product to the Market. Environ. Sci. Technol. 2000, 34, (13), 2690-2696, doi: 109 10.1021/es0000201.

110 3. Lefrancq, M. Transport and attenuation of pesticides in runoff from agricultural 111 headwater catchments: from field characterisation to modelling. Université de Strasbourg, 112 Strasbourg, 2014.

113 4. Elsner, M.; Imfeld, G., Compound-specific isotope analysis (CSIA) of micropollutants in 114 the environment - current developments and future challenges. Current Opinion in 115 Biotechnology 2016, 41, 60-72, doi:10.1016/j.copbio.2016.04.014.

116 5. Mariotti, A.; Germon, J. C.; Hubert, P.; Kaiser, P.; Letolle, R.; Tardieux, A.; Tardieux, P., 117 Experimental determination of nitrogen kinetic isotope fractionation: Some principles; 118 illustration for the denitrification and nitrification processes. Plant Soil 1981, 62, (3), 413-430, 119 doi: 10.1007/BF02374138. 
120 6. Rayleigh, L. Theoretical considerations respecting the separation of gases by diffusion 121 and similar processes. Philosophical Magazine Series 5 1896, 42, (259), 493-498, doi: $122 \quad 10.1080 / 14786449608620944$.

123 7. University of Hertfordshire, The Pesticide Properties DataBase (PPDB) developed by the 124 Agriculture \& Environment Research Unit (AERU), University of Hertfordshire, 2013.

125 8. van der Velde, Y.; Heidbüchel, I.; Lyon, S. W.; Nyberg, L.; Rodhe, A.; Bishop, K.; 126 Troch, P. A., Consequences of mixing assumptions for time-variable travel time distributions. 127 Hydrological Processes 2015, 29, (16), 1099-1085, doi:10.1002/hyp.10372. 